\title{
Economic Growth and the Taylor Rule in the Solow-Tobin Model
}

\author{
Wei-Bin Zhang \\ College of International Management, Ritsumeikan Asia Pacific University, Beppu, Oita, JAPAN \\ E-mail for correspondence: wbz1@apu.ac.jp
}

https://doi.org/10.18034/abr.v9i2.252

\begin{abstract}
The purpose of this study is to study a relationship between growth and inflation with the Taylor rule. We apply the Taylor rule in modelling behavior of central banks to traditional neoclassical growth monetary Solow-Tobin growth model. The household behavior is described by Zhang's concept of disposable income and utility function. Money enters in the individual saving portfolio as in the MIU approach. The model is a synthesis of the basic economic mechanisms in the Solow-Tobin model, the money in utility approach, and the Taylor rule. The wealth accumulation is the key determinant of economic growth like in neoclassical growth theory. Money demand is determined by assuming that the utility is affected by money holding. Money supply is indirectly determined by the Taylor rule. We first build the dynamic model and then simulate the model. We also carry out comparative dynamic analysis with regards to different parameters.
\end{abstract}

Key words: the Solow-Tobin model; the Taylor rule; inflation; growth; MIU approach

\section{INTRODUCTION}

One of most often discussed issues in contemporary economics is about relations between inflation and growth. As with regards to relationship between almost any two closely related variables at any point of time, one may almost certainly find opposite answers in the literature of economics. In a recent review on studies about relationship between economic growth and inflation, Akinsola and Odhiambo (2017) demonstrate that there are varied relations between inflation and growth in the literature. They identified four relations: a) inflation does not have any impact on economic growth (e.g., Sidrauski, 1967; and Cameron et al., 1996); b) inflation has positive relation to economic growth (e.g., Benhabib and Spiegel, 2009); c) inflation has negative relation to economic growth (e.g., Friedman, 1956; Stockman, 1981; Fischer, 1993); d) inflation affects economic growth in terms of specific thresholds (e.g., Aydin et al., 2016). This study is to address issues related to interdependence between inflation and economic growth within an alternative approach. Our model is based on the Solow-Tobin model, the MIU approach, and the Taylor rule.

Taylor rules is referred to how central banks should determine nominal interests as economic conditions are changed. The rule was first suggested by Taylor (1993) and Henderson and McKibbin (1993) for fostering price stability. It is commonly held that the rule has helped central banks in practice. Taylor proposes that the nominal interest rate should be related to the divergences of actual inflation from the targeted inflation rate and actual GDP from the potential GDP. It proposes that the Federal Reserve should enhance interest rates when inflation is high or when employment is higher than full employment levels; on the other hand, the Federal Reserve should reduce interest rates when inflation and employment levels are low. The Taylor rule is a popular way in economics to model monetary policy. Since the seminal work by Taylor, economists have extensively applied the Taylor rule or its generalized forms in theoretical studies on relations between money and economic growth (e.g., Leeper, 1991; Benhabib, et al., 2001; Dupor, 2001; Meng and Yip, 2004; Schmitt-Grohe and Uribe, 2009; Benhabib, et al., 2014). There are different views on the validity of the Taylor rules and different conclusions from applying the rules in different frameworks. The purpose of this study contributes to the literature by applying the Taylor rules to the Solow-Tobin model with the MIU approach and endogenous labor supply.

Tobin (1965) makes a seminal contribution to the theory of monetary growth within the framework of neoclassical growth theory. He is concerned with an isolated economy in which the outside money issued by the government 
competes with real capital in the portfolios of agents by extending the Solow model. The real sector is the same as that in the Solow model. Nevertheless, Tobin did not built his model on microeconomic foundation. An approach to money demand with microeconomic foundation is the socalled money in utility (MIU) function approach. In this approach money yields some services and just directly enters into the utility function. The approach was applied initially by Patinkin (1965), Sidrauski (1967, 1967a) and Friedman (1969). Since then there are different applications of the approach to address various issues related to money and inflation (Feenstra, 1986; Wang and Yip, 1992; Gomme, 1993; Ploeg and Alogoskoufis, 1994; Jones and Manuelli, 1995; Dotsey and Starte, 2000; Chappell and Matthews, 2001; and Handa, 2009). This study is based on the MIU approach with the approach proposed by Zhang $(2008,2013)$. The rest of the paper is organized as follows. Section 2 defines the monetary growth model with the Taylor rule. Section 3 provides differential equations for describing movement of the system and simulates the model. Section 4 carries out comparative dynamic analysis with regards some parameters. Section 5 concludes the study.

\section{THE MONETARY GROWTH MOdeL WITH THE TAYLOR RULE}

The economy is composed of household, one-sector industrial sector, and government. A homogeneous commodity is produced. It can be used for investment and consumption. This model is basically framed as the Tobin monetary growth model (Tobin, 1965; Nagatani, 1970), except the determination of money demand and money supply. The one sector is the same as the production sector as in neoclassical growth theory (e.g., Solow, 1956; Uzawa, 1961; Burmeister and Dobell, 1970; Azariadis, 1993; Barro and Sala-i-Martin, 1995). Firms use capital and labor as input factors. Money does not directly affect production, but money enters the utility function. Exchanges take place in perfectly competitive markets. Factor markets work well; factors are in elastically supplied and the available factors are fully utilized at every moment. The economy has three assets, money, bond issued by the government, and capital. There is a fixed number of homogeneous households, denoted by $\bar{N}$. The household can hold three assets. The nominal bonds pay the (positive) nominal interest rate $R(t)$, which will be determined by the government by the Taylor rule. Let $P(t)$ represent the nominal price and $\pi(t)$ the inflation rate. We have: $\pi(t)=\dot{P}(t) / P(t)$.

\section{Labor supply}

Let $T(t)$ stand for the work time of a representative household and $N(t)$ for the flow of qualified labor services used at time $t$ for production. We have $N(t)$ as follows:

$N(t)=T(t) \bar{N}$.

\section{Production sector}

We use the following Cobb-Douglas production function $F(t)$ to describe a relationship between inputs and output:

$F(t)=A K^{\alpha}(t) N^{\beta}(t), \alpha, \beta>0, \alpha+\beta=1$,

in which $A, \alpha$, and $\beta$ are positive parameters. The rate of interest $r(t)$ and real wage rate $w(t)$ are determined by markets. Hence, for any individual firm $r(t)$ and $w(t)$ are given at each point of time. The production sector chooses the two variables $K(t)$ and $N(t)$ to maximize its profit. The marginal conditions are given by:

$r(t)+\delta_{k}=\frac{\alpha F(t)}{K(t)}, w(t)=\frac{\beta F(t)}{N(t)}$,

where $\delta_{k}$ is the fixed depreciation rate of physical capital and

$\mathrm{r}(t) \equiv R(t)-\pi(t)$

\section{Disposable income}

We apply the concept of disposable income and utility proposed by Zhang $(1993,2005)$. Consumers make decisions on choice of consumption level of commodity, saving, and money holding. In this study, we follow Zhang $(2008,2013)$ in modeling choice of money. The representative household holds nominal government bonds, denoted by $B(t)$, that pay the nominal interest rate. The representative household holds money $M(t)$. The preference over current and future consumption is reflected in the consumer's preference structure over leisure, money, consumption and saving. We use $\bar{\tau}$ to stand for the (fixed) real lump-sum taxes. The household current income from the interest payment $r(t) \bar{k}(t)$, the wage payments $T(t) w(t)$, the cost of holding money $\pi(t) m(t)$ is given by:

$$
\begin{aligned}
& y(t)=r(t)(\bar{k}(t)+b(t))+T(t) w(t)-\frac{\dot{B}(t)}{P(t)}-\frac{\dot{M}(t)}{P(t)}- \\
& \pi(t) m(t)-\bar{\tau},
\end{aligned}
$$

where

$m(t) \equiv \frac{M(t)}{P(t)}, \quad b(t) \equiv \frac{B(t)}{P(t)}$.

The total value of wealth of the representative household is $a(t)$ where:

$a(t) \equiv \bar{k}(t)+b(t)+m(t)$

The disposable income of a household is defined as the sum of the current income and the wealth available for purchasing consumption goods and saving, $\hat{y}(t)=y(t)+$ $a(t)$. That is:

$\hat{y}(t)=a(t)+y(t)$.

The disposable income is used for saving, consumption, and money holding.

Denote $\bar{T}(t)$ the time spent on leisure. Let the (fixed) total available time be denoted by $T_{0}$. The time constraint is expressed by: 
$T(t)+\bar{T}(t)=T_{0}$.

Insert (6) in (5)

$\hat{y}(t)=\bar{y}(t)+m(t)-\bar{T}(t) w(t)-\pi(t) m(t)$,

where

$$
\begin{aligned}
\bar{y}(t) \equiv(1+r(t)) & (\bar{k}(t)+b(t))+T_{0} w(t)-\frac{\dot{B}(t)}{P(t)} \\
- & \frac{\dot{M}(t)}{P(t)}-\bar{\tau} .
\end{aligned}
$$

\section{Utility function and optimal behavior}

The household's utility function for enjoying leisure, holding money, consuming goods, and making saving is be represented by the following utility function:

$U(t)=\bar{T}^{\sigma_{0}}(t) m^{\varepsilon_{0}}(t) c^{\xi_{0}}(t) s^{\lambda_{0}}(t), \sigma_{0}, \varepsilon_{0}, \xi_{0}, \lambda_{0}>0$,

where $\sigma_{0}$ is the propensity to enjoy leisure time, $\varepsilon_{0}$ is propensity to hold money, $\xi_{0}$ the propensity to consume, and $\lambda_{0}$ the propensity to own wealth. This utility function is applied to different economic problems. A detailed explanation of the approach and its applications to different problems of economic dynamics are provided in Zhang (2005, 2008). The disposable income is spent on holding money, consumption of the good, and saving. We have:

$(1+R(t)) m(t)+c(t)+s(t)=\hat{y}(t)$.

Insert (7) in (9)

$w(t) \bar{T}(t)+\bar{\pi}(t) m(t)+c(t)+s(t)=\bar{y}(t)$,

where

$\bar{\pi}(t) \equiv \pi(t)+R(t)$.

The consumer problem is to choose current money, leisure time, consumption, and saving so that the utility is maximized. Maximizing $U(t)$ subject to (10) yields:

$w(t) \bar{T}(t)=\sigma \bar{y}(t), \bar{\pi}(t) m(t)=\varepsilon \bar{y}(t), c(t)=\xi \bar{y}(t)$,

$s(t)=\lambda \bar{y}(t)$,

where

$$
\begin{gathered}
\sigma \equiv \rho \sigma_{0}, \varepsilon \equiv \rho \varepsilon_{0}, \quad \xi \equiv \rho \xi_{0}, \lambda \equiv \rho \lambda_{0}, \quad \rho \\
\equiv \frac{1}{\varepsilon_{0}+\xi_{0}+\lambda_{0}+\sigma_{0}} .
\end{gathered}
$$

It should be noted that in the Baumol-Tobin model (Baumol, 1952, Tobin, 1956; Romer, 1986), the demand for money is derived as follows:

$\frac{M}{P} \equiv\left(\frac{C Y}{2 r}\right)^{1 / 2}$,

where $C$ is the fixed transaction cost per transfer and $Y$ is disposable income. It can be seen that our demand function is quite similar to the Baumol-Tobin model, even though they are derived from different mechanisms.

\section{Wealth dynamics}

The change in wealth is saving minus dissaving:

$\dot{a}(t)=s(t)-a(t)$.

\section{Monetary and fiscal policy}

We apply an alternative Taylor rule to model monetary policy. The rule suggested by Taylor (1993) is as follows:

$$
\begin{gathered}
R(t)=\pi(t)+r^{*}(t)+0.5\left(\pi(t)-\pi^{*}(t)\right) \\
+0.5\left(y(t)-y^{*}(t)\right),
\end{gathered}
$$

where is $r^{*}(t)$ the assumed equilibrium real interest rate, $\pi^{*}(t)$ is the desired rate of inflation, $y(t)$ is the logarithm of real GDP, and $y^{*}(t)$ is the logarithm of potential real GDP. The rule implies that if inflation is above its target or output is above its full-employment level, the central bank should enhance the interest rate in order to reduce inflationary pressure. We assume that the monetary authority follows an interest rate feedback rule as follows:

$R(t)=R(\pi(t)) \geq 0$.

The monetary policy is called active (passive) at an inflation rate $\pi$ if $R^{\prime}(\pi)>(<) 1$. In particular, we follow Benhabib et al. (2001) in assuming that the monetary authority sets the nominal interest as follows:

$R(t)=q_{0} e^{q\left(\pi(t)-\pi^{*}\right)}, q_{0}, q, \pi^{*}>0$,

where $q_{0}, q$ and $\pi^{*}$ are parameters. It can be seen that as the nominal rate of interest changes in the same direction as the inflation rate.

\section{The government's budget constraint}

The government prints money $M(t)$ and issues nominal bonds $B(t)$. We neglect any possible government consumption on supplying public goods. The government pays the nominal interest rate to its bonds. The government's flow budget constraint is given by:

$\dot{B}(t)=R(t) B(t)-\dot{M}(t)-P(t) \bar{\tau}$.

\section{Capital change}

The change in capital stock is equal to the net of output, consumption and depreciation as follows:

$\dot{K}(t)=F(t)-\bar{N} c(t)-\delta_{k} K(t)$.

We have thus built the dynamic model. We now examine its dynamics. It can be seen that if we omit the money, our model is the same as the Solow one sector model.

\section{THE DYNAMICS OF THE ECONOMIC SYSTEM}

We first provide two differential equations to give motion of two variables and a computational procedure to follow the motion of all the variables. The following lemma is proved in the Appendix. 


\section{Lemma}

The motion of the economic system is given two differential equations with $\bar{k}(t)$ and $\pi(t)$ as the variables:

$\dot{\bar{k}}(t)=\varphi_{k}(\bar{k}(t), \pi(t))$,

$\dot{\pi}(t)=\varphi_{\pi}(\bar{k}(t), \pi(t)),(16)$

where $\varphi_{k}$ and $\varphi_{\pi}$ are functions of $\bar{k}(t)$ and $\pi(t)$ defined in the Appendix. We determine the rest variables by the following procedure: $z(t)$ by (A3) $\rightarrow r(t)$ and $w(t)$ by $(\mathrm{A} 2) \rightarrow R(t)$ by $(13) \rightarrow K(t)=\bar{k}(t) \bar{N} \rightarrow b(t)$ by (A14) $\rightarrow$ $m(t)$ by $(\mathrm{A} 6) \rightarrow P(t)=P_{0} e^{\int_{0}^{t} \pi d x} \rightarrow B(t)=P(t) b(t) \rightarrow$ $M(t)=P(t) m(t) \rightarrow \bar{y}(t)$ by (A5) $\rightarrow c(t), s(t)$, and $\bar{T}(t)$ by $(11) \rightarrow T(t)$ by (6) $\rightarrow N(t)$ by (1) $\rightarrow F(t)$ by (A4).

The Lemma is important as it tells us how to follow the motion of the economic system, given proper initial conditions. With computer it is straightforward to reveal the motion of the dynamic economic system. As the expressions are too tedious, we cannot easily explicitly interpret the analytical results. We specify the parameter values as follows:

$\bar{N}=50, T_{0}=24, \alpha=0.33, A=1.5, \pi^{*}=0.01, \bar{\tau}=1$,

$\lambda_{0}=0.6$,

$\xi_{0}=0.1, \sigma_{0}=0.18, \varepsilon_{0}=0.005, \mathrm{q}_{0}=0.01, \mathrm{q}=150$,

$\delta_{k}=0.03$.

The population is 50 . The total available time is 24 . The target inflation rate is 1 percent. The propensity to save is 0.6 . The propensities to consume goods and use leisure time are respectively 0.1 and 0.18 . The propensity to hold money is 0.005 . We demonstrate that with the above specified parameters, the system has a unique equilibrium point. The equilibrium values of the variables are as follows:

$$
\begin{aligned}
& \begin{aligned}
F=846.1, \quad N= & 362, K=3897.5, \mathrm{R}=0.201, \mathrm{r} \\
& =0.171,
\end{aligned} \\
& \begin{aligned}
\pi=0.03, \quad w= & 1.57, \quad m=3.16, \quad b=6.4, \quad \bar{k}=78, a \\
& =87.5,
\end{aligned} \\
& c=14.6, \quad T=7.24 .
\end{aligned}
$$

The long-run inflation rate is 3 percent. The two eigenvalues are:

$\{0.349,-0.234\}$.

The equilibrium point is a saddle point. We specify the following initial conditions:

$\bar{k}(0)=77, \pi(0)=0.029$.

The changes of the variables over time are plotted in Figure 1. The national output rises over time from the initial state. Similarly, the other real variable variables fall. The household works more hours. The nominal rate falls in association with falls in the inflation rate. The real money holding rises. The real bond falls.
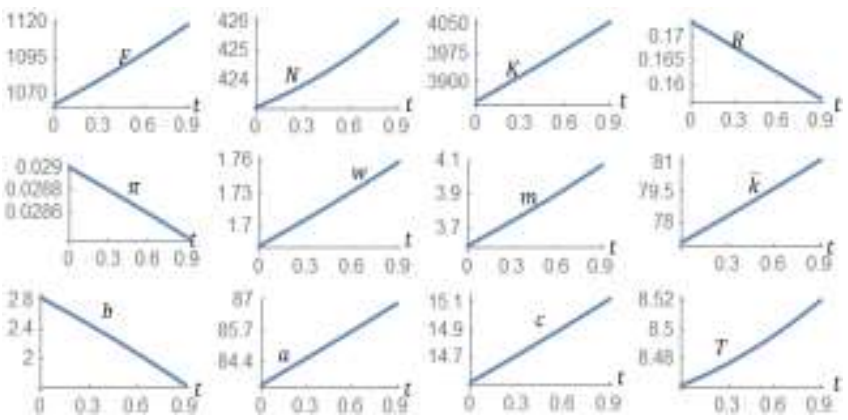

Figure 1: The Motion of the System with Wealth and Money

\section{Comparative DyNAmic ANALYSIS}

The previous section identified the equilibrium point of the dynamic economy and demonstrates that the economic system is neutral. This section examines impact of changes in some parameters on the dynamics of the system. First, we introduce a symbol $\bar{\Delta}$ to stand for the change rate in term of percentage due to the parameter change.

\section{The targeted inflation rate is enhanced}

We firstly study what happen to the economy if the targeted inflation rate is enhanced as follows: $\pi_{0}=0.01$ to 0.0102 . The nominal rate of interest is reduced. The actual Inflation rate is reduced. The real wage is increased. The money holding is increased. The household works more hours and the labor supply rises. The wealth per household is increased. The physical wealth is increased. The bond is reduced. The output is increased.
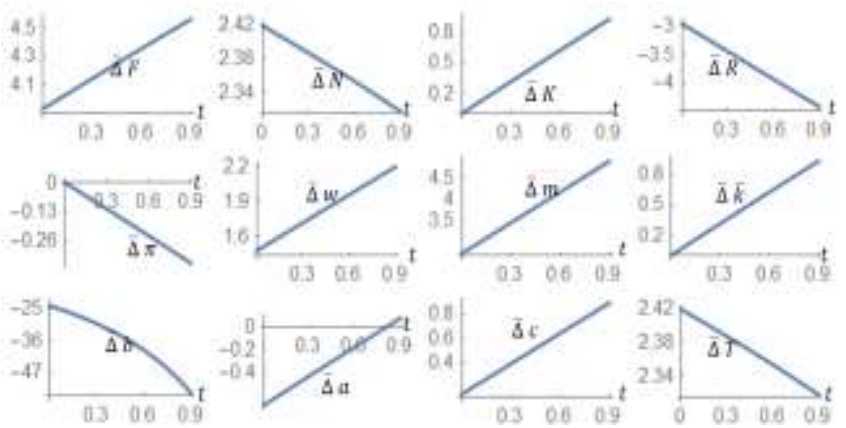

Figure 2: The Targeted Inflation Rate is enhanced

\section{The total factor productivity is enhanced}

We now examine the impact of the following technological improvement: $A=1.5$ to 1.55 . The nominal rate of interest is reduced. The actual Inflation rate is reduced. The real wage is increased. The money holding is increased. The household works more hours and the labor supply rises. The wealth per household is reduced initially but is increased in the long term. The physical wealth is increased. The bond is reduced. The output is enhanced. 

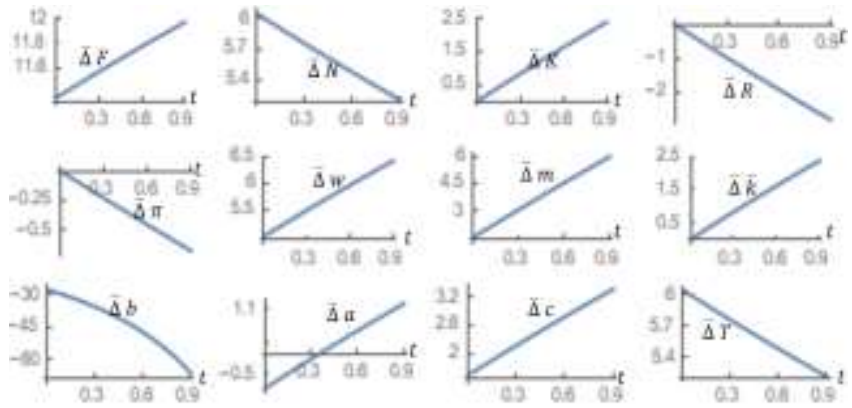

Figure 3: The Total Factor Productivity is enhanced

\section{The propensity to hold money is enhanced}

We now examine the impact of the following increase in the propensity to hold money: $\epsilon_{0}=0.005$ to 0.006 . The household holds more money. The nominal rate of interest is reduced. The actual Inflation rate is reduced. The real wage is increased. The household works more hours and the labor supply rises. The wealth per household is reduced. The physical wealth is increased. The bond is reduced. The output is enhanced. The household consumes less initially but more in the long term.
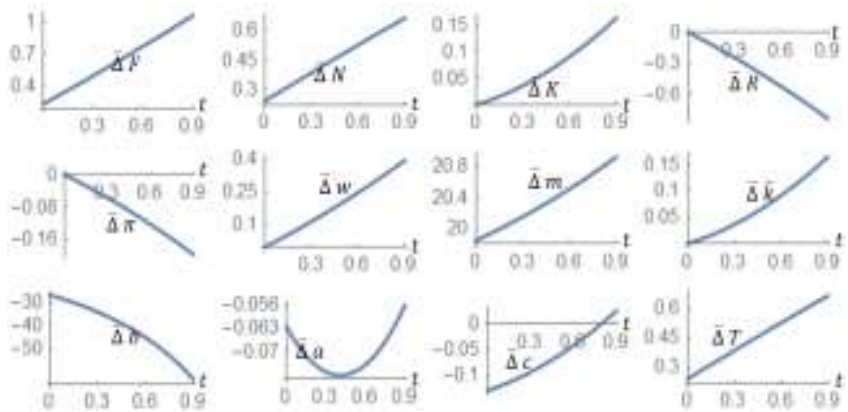

Figure 4: The Propensity to Hold Money is enhanced

\section{An increase in the propensity to save}

We now examine the impact of the following increase in the propensity to save: $\lambda_{0}=0.6$ to 0.61 The household has less wealth initially but more in the long term. The bond falls. The physical wealth is increased. The household holds more money. The nominal rate of interest and inflation rate are reduced. The real wage is increased. The household works more hours and the labor supply rises. The physical wealth is increased. The output is enhanced. The household consumes less.
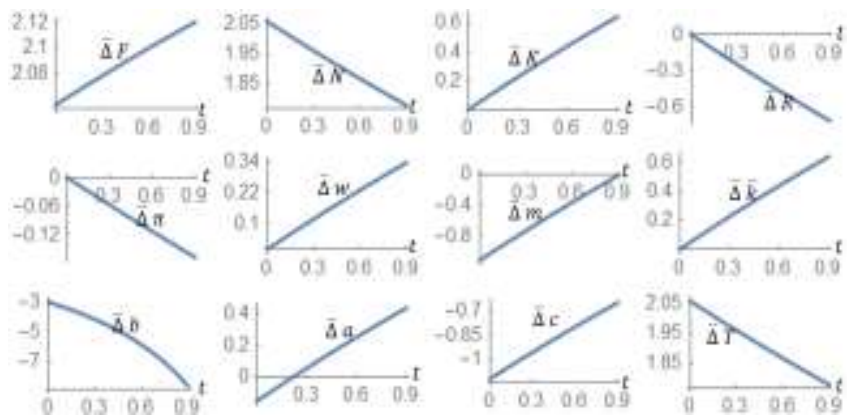

Figure 5: An Increase in the Propensity to Save

\section{A rise in the propensity to use leisure time}

We now examine the impact of the following increase in the propensity to use leisure time: $\sigma 0=0.18$ to 0.19 . The household works less hours. The total labor supply is reduced. The national output falls. The national physical stock falls. The bond rises. The wealth per household rises initially but falls in the long term. The physical wealth is reduced. The household holds less money. The nominal rate of interest and inflation rate are increased. The real wage is reduced. The household consumes less.
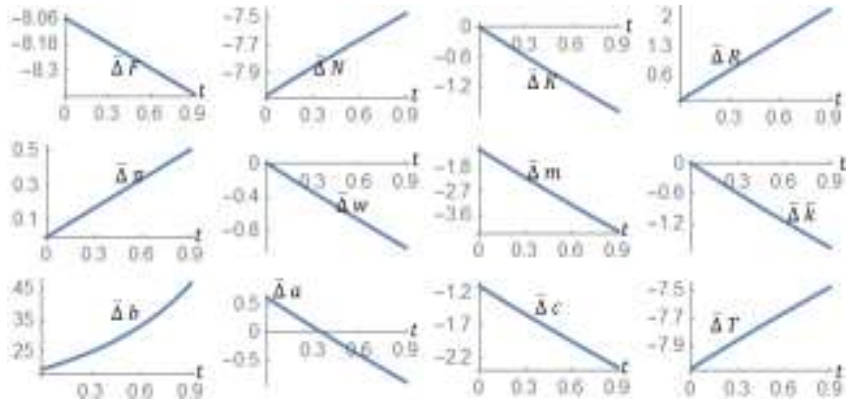

Figure 6: A Rise in the Propensity to Use Leisure Time

\section{The tax is increased}

We now examine the impact of the following increase in the propensity to use leisure time: $\bar{\tau}=1$ to 1.1 . The nominal interest rate and inflation rate are reduced. The household works more hours. The total labor supply is increased. The national output rises. The national physical stock rises. The bond rises initially but falls in the long term. The wealth per household rises. The physical wealth is reduced. The household holds less money. The nominal rate of interest and inflation rate are increased. The real wage is increased. The household consumes more.
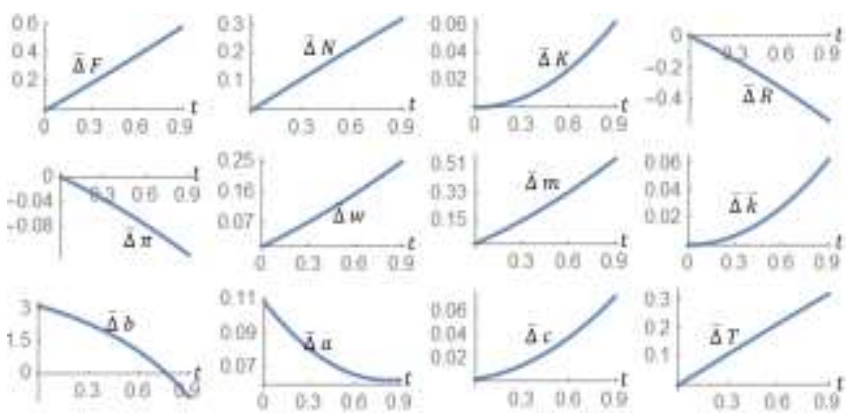

Figure 7: The Tax is increased

\section{CONCLUSIONS}

Basing on the Solow-Tobin growth model, we apply the Taylor rule in illustrating behavior of the central banks. The household behavior is described by Zhang's concept of disposable income and utility function. Money enters in the individual saving portfolio as in the MIU approach. The dynamic model is built with microeconomic foundation. Our model is a synthesis of the basic economic mechanisms in the Solow-Tobin model, the money in utility approach, and the Taylor rule. The wealth 
accumulation is the key determinant of economic growth like in neoclassical growth theory. Money demand is determined by assuming that the utility is affected by money holding. Money supply is indirectly determined by the Taylor rule. We first built the dynamic model and then simulated the model. We also carried out comparative dynamic analysis with regards to different parameters. Our comparative analysis provided some insights into relations between growth and inflation over the whole dynamic process rather than only with regards to steady states as in most of the theoretical literature of monetary growth. For instance, after comprehensively and extensively reviewing the literature of both empirical and theoretical researches on growth and inflation, Akinsola and Odhiambo (2017) show that there is an "overwhelming support in favour of a negative relationship between inflation and growth, especially in developed economies." From the figures of the comparative dynamic analysis we conclude that the change rate in the national output is opposite to that in the inflation rate. In fact, as in many other studies about the issues related to growth and inflation policy, this study does not guarantee that the inflation policy is associated with stability of the monetary economy. Without guaranteed stability, long-run effects of policy changes are not easy to know. This also hints on why many countries have frequently changed their inflation policies often without achieving the expected results. It is well known that one-sector growth model has been generalized and extended in many directions. It is not difficult to generalize our model along these lines in the literature. The Taylor rule has different formations in the contemporary literature on money, inflation and growth. We may generalize our model with other forms of production or utility functions.

\section{ApPendix: Proving the LeMmA}

From (3), we obtain:

$z \equiv \frac{r+\delta_{k}}{w}=\frac{\bar{\beta} N}{K},(A 1)$

where $\bar{\beta} \equiv \alpha / \beta$ and the time index is suppressed wherever no confusion. From (A1) and (3), we obtain:

$w=\beta A\left(\frac{\bar{\beta}}{z}\right)^{\alpha}, r=z w-\delta_{k}$.

We note that $r$ and $w$ are uniquely determined as functions of $z$ by (A2). From (2) we get:

$z(\pi)=\bar{\beta}^{-\alpha / \beta}\left(\frac{r+\delta_{k}}{\beta A}\right)^{1 / \beta}$.

From (3) we have

$\mathrm{F}=\frac{w N}{\beta}$.

Insert (14) in the definition of $\bar{y}$ :

$\bar{y}=\varphi_{0}+\pi b,(\mathrm{~A} 5)$ where

$\varphi_{0}(\bar{k}, \pi) \equiv(1+r) \bar{k}+T_{0} w$.

From (A5) and (11) we have:

$m(\bar{k}, b, \pi)=\varphi+\frac{\varepsilon \pi b}{\bar{\pi}}$,

where

$\varphi(\bar{k}, \pi) \equiv \frac{\varepsilon \varphi_{0}}{\bar{\pi}}$.

From (11), (A5) and (6) we have:

$T=(1-\sigma) T_{0}-\left(\frac{1+r}{w}\right) \sigma \bar{k}-\frac{\sigma \pi b}{w}$.

By the definitions we have:

$\dot{m}=\frac{\dot{M}}{P}-\pi m, \dot{b}=\frac{\dot{B}}{P}-\pi b$. (A8)

Insert (A8) in (14)

$\dot{b}+\dot{m}=R b-\pi m-\pi b-\bar{\tau}$. (A9)

By (15), (A4) and $\mathrm{K}=\bar{k} \bar{N}$, we have

$\dot{\bar{k}}=\frac{w T}{\beta}-c-\delta_{k} \bar{k} .(A 10)$

From (A10) and (11), we have:

$\dot{\bar{k}}=\varphi_{k} \equiv \frac{w T}{\beta}-\xi \bar{y}-\delta_{k} \bar{k}$.

From (12) and (11), we have:

$\dot{\bar{k}}+\dot{b}+\dot{m}=\lambda \bar{y}-\bar{k}-b-m .(A 12)$

Inserting (A9) in (A12), we have

$\dot{\bar{k}}+R b-\pi m-\pi b-\bar{\tau}=\lambda \bar{y}-\bar{k}-b-m$.

Insert (A11) in the above equation

$W+R b+(1-\pi) m-\pi b=\bar{\xi} \bar{y}-b$,

where

$W(\bar{k}, \pi) \equiv \frac{w T_{0}}{\beta}+\left(1-\delta_{k}\right) \bar{k}-\bar{\tau}, \bar{\xi} \equiv \xi+\lambda+\frac{\sigma}{\beta}$.

Insert (A5) and (A6) in (A13)

$b=\tilde{\varphi}(\bar{k}, \pi) \equiv \frac{\bar{\xi} \varphi_{0}-(1-\pi) \varphi-W}{\varphi_{1}}$,

where

$\varphi_{1}(\bar{k}, \pi) \equiv R+\frac{(1-\pi) \varepsilon \pi}{\bar{\pi}}+1-\pi-\bar{\xi} \pi$.

Insert (A7), (A5) and (A14) in (A11)

$\dot{\bar{k}}=\varphi_{k}(\bar{k}, \pi) \equiv \frac{w T}{\beta}-\xi \bar{y}-\delta_{k} \bar{k}$.

From (A6) and (A14), we have 
$b+m=\Psi(\bar{k}, \pi) \equiv \tilde{\varphi}+\varphi+\frac{\varepsilon \pi \tilde{\varphi}}{\bar{\pi}}$

Take derivatives of (A16) with respect to $t$ :

$\dot{b}+\dot{m}=\frac{\partial \Psi}{\partial \bar{k}} \dot{\bar{k}}+\frac{\partial \Psi}{\partial \pi} \dot{\pi}$. (A17)

Insert (A9) and (A15) in (A17)

$$
\begin{aligned}
\dot{\pi}=\varphi_{\pi}(\bar{k}, \pi) \equiv & (R \tilde{\varphi}-\pi m-\pi \tilde{\varphi}-\bar{\tau} \\
& \left.-\varphi_{k} \frac{\partial \Psi}{\partial \bar{k}}\right)\left(\frac{\partial \Psi}{\partial \pi}\right)^{-1} .(A 18)
\end{aligned}
$$

Equations (A15) and (A18) have two differential equations with two variables. We thus can determine $\bar{k}(t)$ and $\pi(t)$ by (A9) and (A17). Once we determine the values of $\bar{k}(t)$ and $\pi(t)$, we determine the rest variables by the procedure in the Lemma. In summary, we proved the Lemma.

\section{REFERENCES}

Akinsola, F.A. and Odhiambo, N.M. (2017), Inflation and economic growth: A review of the international literature. Comparative Economic Research 20, 41-56.

Aydin, C., Esen, O., and Bayrak, M. (2016), Inflation and economic growth: A dynamic panel threshold analysis for Turkish republics in transition process. Procedia - Social and Behavioral Sciences 229, 196-205.

Azariadis, C. (1993), Intertemporal Macroeconomics. Oxford: Blackwell.

Barro, R.J. and X. Sala-i-Martin (1995), Economic Growth. New York: McGraw-Hill, Inc.

Baumol, W.J. (1952), The transactions demand for cash: An inventory theoretic approach. Quarterly Journal of Economics $66,545-56$.

Benhabib, J., Evans, G.W., and Honkapohja, S. (2014), Liquidity traps and expectation dynamics: Fiscal stimulus or fiscal austerity. Journal of Economic Dynamics \& Control 45, 220-38.

Benhabib, J., Schmitt-Grohe, S, and Uribe, M. (2001), The perils of Taylor rules. Journal of Economic Theory 96, 40-69.

Benhabib, J. and Spiegel, M.M. (2009), Moderate inflation and the deflation - Depression link. Journal of Money, Credit and Banking 41, 787-98.

Burmeister, E. and Dobell, A.R. (1970), Mathematical Theories of Economic Growth. London: Collier Macmillan Publishers.

Cameron, N., Hum, D. and Simpson, W. (1996), Stylized facts and stylized illusion: Inflation and productivity revisited. Canadian Journal of Economics 29, 152-62.

Chappell, D. and Matthews, K. (2001), Monetary disequilibrium, endogenous money, stability and the determinacy of inflation. Economic Notes 30, 145-61.

Dotsey, M. and Sarte, P.D.G. (2000), Inflation uncertainty and growth in a cash-in-advance economy. Journal of Monetary Economics 45, 631-55.

Dupor, B. (2001), Investment and interest rate policy. Journal of Economic Theory 98, 85-115.
Feenstra, R.C. (1986), Functional equivalence between liquidity costs and the utility of money. Journal of Monetary Economics $17,271-92$.

Fischer, S. (1993), The role of macroeconomic factors in growth. Journal of Monetary Economics 32, 485-512.

Friedman, M. (1956), The quantity theory of money: A restatement, in Friedman, M. (Ed.), Studies in the Quantity Theory of Money, pp. 3-21. Chicago: University of Chicago Press.

Friedman, M. (1969), The optimum quantity of money, in The Optimum Quality of Money and Other Essays, edited by Friedman, M. Chicago: Aldine.

Handa, J. (2009), Monetary Economics. London: Routledge.

Henderson, D.W. and McKibbin, W. (1993), A comparison of some basic monetary policy regimes for open economies: Implications of different degrees of instrument adjustment and wage persistence. Carnegie-Rochester Conference Series on Public Policy 39, 221-318.

Gomme, P. (1993), Money and growth revisited: Measuring the costs of inflation in an endogenous growth model. Journal of Monetary Economics 32, 51-77.

Jones, L.E. and Manuelli, R.E. (1995), Growth and the effects of inflation. Journal of Economic Dynamics and Control 19, 1405-28.

Leeper, E. (1991), Equilibrium under 'active' and 'passive' monetary and fiscal policies. Journal of Monetary Economics $27,129-47$.

Meng, Q.L. and Yip, C.Y (2004), Investment, interest rate rules, and equilibrium determinacy. Economic Theory 23, 863-78.

Nagatani, K. (1970), A note on professor Tobin's “Money and Economic Growth". Econometrica 38,171-75.

Patinkin, D. (1965), Money, Interest, and Prices: An Integration of Monetary and Value Theory, $2^{\text {nd }}$ edition. New York: Harper \& Row.

Ploeg, F. van der and Alogoskoufis, G.S. (1994), Money and endogenous growth. Journal of Money, Credit and Banking 26 , 771-91.

Romer, D. (1986), A simple general equilibrium version of the Baumol-Tobin model. Quarterly Journal of Economics 101, 663-86.

Schmitt-Grohe, S, and Uribe, M. (2009), Liquidity traps with global Taylor rules. International Journal of Economic Theory 5 , 85-106.

Sidrauski M (1967), Inflation and economic growth. Journal of Political Economy 75, 789-810.

Sidrauski M (1967a), Rational choice and patterns of growth in a monetary economy. American Economic Review 57, 534-44.

Solow, R. (1956), A contribution to the theory of economic growth. Quarterly Journal of Economics 70, 65-94.

Stockman, A.C. (1981), Anticipated inflation and the capital stock in a cash-in-advance economy. Journal of Monetary Economics 8, 387-93.

Taylor, J.B. (1993), Discretion versus policy rules in practice. Carnegie-Rochester Conference Series on Public Policy 39, 195214.

Tobin, J. (1956), The interest elasticity of the transactions demand for cash. Review of Economics and Statistics 38, 241-47. 
Tobin, J. (1965), Money and economic growth. Econometrica 33, 671-84.

Uzawa, H. (1961), On a two-sector model of economic growth. Review of Economic Studies 29, 47-70.

Wang, P. and Yip, C.K. (1992), Examining the long-run effect on economic growth. Journal of Macroeconomics 14, 359-69.

Zhang, W.B. (1993), Woman's labor participation and economic growth - creativity, knowledge utilization and family preference. Economics Letters 42, 105-110.
Zhang, W.B. (2005), Economic Growth Theory. London: Ashgate.

Zhang, W.B. (2008), Monetary Growth Theory: Money, Interest, Prices, Capital, Knowledge, and Economic Structure over Time and Space. London: Routledge.

Zhang, W.B. (2013), Education, endogenous human capital, and monetary economic growth with MIU approach. The Czech Economics Review 7, 100-18.

$--0--$

\section{Acknowledgements}

The author is grateful to the constructive comments of the two anonymous referees.

Online Archive: https://abc.us.org/ojs/index.php/abr/issue/archive 